\title{
Federalismo Fiscal Market-Preserving: uma análise de Equilíbrio Geral Computável para o Brasil
}

\author{
Marcos Spínola Nazareth ${ }^{1}$ \\ Angelo Costa Gurgel ${ }^{2}$ \\ Wilson da Cruz Vieira ${ }^{3}$
}

\section{Resumo}

O propósito central do federalismo é prover uma estrutura estável de descentralização política. No Brasil, ao contrário disso, tem havido recorrentemente períodos de descentralização e centralização fiscal com impactos na performance da economia. A literatura mais recente prevê problemas de incentivos para os governos em ambos os arranjos fiscais. Assim, o objetivo desse artigo foi testar empiricamente a validade da principal proposição do federalismo market-preserving (FMP), qual seja: maior autonomia tributária aos governos regionais disciplinada por imposição de restrição orçamentária rígida e mobilidade de fatores inter-regional, eleva o desempenho econômico. Para isso, foram conduzidos diversos experimentos num modelo de equilíbrio geral computável, que buscaram simular as diferentes intensidades dessas características do FMP. De maneira geral, os resultados confirmam que a economia nacional melhora sua performance (aumentos de PIB e bem-estar), embora em nível regional, em algumas situações, haja aumento das desigualdades.

\section{Palavras-Chave}

Descentralização fiscal. Restrição orçamentária rígida. Modelos EGC.

\begin{abstract}
The purpose of a federal system is to provide a stable political decentralization structure. In Brazil, on the other hand, there has been sequential periods of fiscal decentralization and centralization with impacts on the economic performance. The most recent literature predicts problems of incentives for governments in both movements. Thus, this paper aims to test empirically the validity of the main market-preserving federalism proposition (MPF), which is:

- O presente trabalho foi realizado com apoio da Coordenação de Aperfeiçoamento de Pessoal de Nível Superior - Brasil (CAPES) - Código de Financiamento 001.

1 Pesquisador PAEG - Universidade Federal de Viçosa (UFV) - Endereço: Av. P. H. Rolfs, s/n Viçosa/MG - Brasil - CEP: 36570-900 - E-mail: marcos.nazareth@ufv.br ORCiD: https://orcid.org/0000-0002-6797-7241.

2 Professor - Escola de Economia de São Paulo - Fundação Getúlio Vargas (EESP-FGV). Endereço: Rua Itapeva, 474, 6ªndar - São Paulo/SP - Brasil - CEP: 01332-000.

E-mail: angelo.gurgel@fgv.br - ORCiD: https://orcid.org/0000-0001-8331-9508.

3 Professor - Universidade Federal de Viçosa (UFV) - Endereço: Av. P. H. Rolfs, s/n - Viçosa/MG - Brasil. CEP: 36570-900 - E-mail: wvieira@ufv.br - ORCiD:https://orcid.org/0000-0001-8247-6536. Recebido: 25/10/2017. Aceite: 11/10/2018.
\end{abstract}

(c) (i) (\$) Esta obra está licenciada com uma Licença Creative Commons Atribuição-Não Comercial 4.0 Internacional. 
more tax autonomy to regional governments, disciplined by imposing hard budget constraint and interregional factor mobility, raises de economic gains. For this, some experiments were carried out in a computable general equilibrium model seeking to simulate the different intensities of these MPF characteristics. In general, the results confirm that the Brazilian economy improves its performance (increases in GDP and welfare). However, at regional level and in some situations, there is an increase in inequalities.

\section{Keywords}

Fiscal decentralization. Hard budget constraint. CGE models.

\section{Classificação JEL}

D58. H72. H77.

\section{Introdução}

O objetivo principal do sistema federativo é prover um sistema estável de descentralização político-fiscal. Avaliar, portanto, a estrutura federativa de uma nação é particularmente crucial porque, segundo Weingast (1995), foi um dos mais importantes mecanismos que permitiram forte desenvolvimento de muitas nações do mundo ocidental nos últimos dois séculos, especialmente o federalismo market-preserving, que limita a capacidade dos governos de violarem o funcionamento do mercado e serem discricionários no tempo.

No Brasil, Rezende e Afonso (2004) constataram que uma das grandes marcas do federalismo brasileiro ao longo de sua história é a alternância de responsabilidades fiscais entre as esferas de governo. Desde a promulgação da primeira Constituição após a independência, em 1824, ${ }^{1}$ seguem-se períodos de descentralização e centralização com as Constituições marcando o giro do "pêndulo" para uma das direções e sempre como reação aos problemas gerados no período anterior, com impactos na performance econômica do país. ${ }^{2}$

1 Somente nesta primeira constituição o governo era oficialmente unitário, não federativo. Porém, o que importa para análise econômica não é exatamente o que se tem formalmente, mas sim o efetivo ambiente institucional proporcionado pelo regime.

2 Os trabalhos de Cossio (2002) e Serra e Afonso (1999) discutem esse aspecto amplamente. 
Consequentemente, o problema central do federalismo brasileiro desde suas origens é a permanente instabilidade do arranjo político-fiscal, contínuas variações na composição fiscal entre esferas de governos com ausência de regras (constitucionais ou não) fiscais críveis, resultando em uma estrutura de incentivo deficiente. Ademais, a situação típica é de um ambiente sem restrição orçamentária rígida nas finanças públicas, somada aos naturais custos de mobilidade de fatores característicos de economias pouco desenvolvidas - por exemplo, altos custos de transportes e telecomunicações e mercado de capitais restrito. Como consequência disso, têm-se constantes desequilíbrios fiscais de todo o setor público que afetam negativamente os resultados econômicos do país. ${ }^{3}$

Nesse sentido, a teoria mais recente prevê problemas de incentivos com a centralização e com descentralização, o denominado "dilema gêmeos do federalismo" (Weingast 1995). A centralização tende a distanciar a decisão de gasto dos governos das preferências dos cidadãos ocasionando ineficiências alocativas e favorece a excessiva dependência das unidades subnacionais por recursos federais acarretando problemas diversos como o da ilusão fiscal e o efeito flypaper ${ }^{4}$ com a consequente subestimativa do custo dos bens e serviços públicos.

Por outro lado, a descentralização fiscal pode produzir aumento de déficits fiscais subnacionais em função de disputas entre jurisdições; ${ }^{5}$ elevação de despesas públicas locais causada por externalidades e efeitos de spillovers, que geram problemas típicos de free-riding e recurso comum, ${ }^{6}$ isto é, aumentam-se os endividamentos subnacionais porque transfere-se para a União ("o fundo comum") a responsabilidade deste pegando carona na coletividade; e, por último, provável agravamento de desigualdades inter-regionais em virtude da repercussão das disparidades socioeconômicas na capacidade de geração de receita própria entre jurisdições.

Por causa disso, segundo Weingast (2005), a solução para esse dilema é estabelecer regras institucionais ou uma estrutura federativa que resolva

3 Ver, além dos já citados, Varsano (1996) e Abreu (1990).

4 No final das contas, este é fruto daquele. O flypaper effect afirma que os gastos dos governos subnacionais aumentam mais quando os recursos para financiá-los provêm de transferências da União do que se tivessem sido obtidos por meio de arrecadação tributária própria. Segundo a teoria, o mecanismo que permite esse resultado é o fiscal illusion dos contribuintes.

5 O fenômeno da guerra fiscal entre estados, por exemplo, foi algo recorrente no Brasil nos anos 90. É bom frisar que isso não é necessariamente um problema se não houver geração de déficits.

6 O conhecido "tragédia dos comuns", resultado não cooperativo em contextos em que agentes econômicos utilizam algum recurso comum, isto é, o consumo excessivo e, portanto, subótimo do recurso. 
simultaneamente os dois problemas, melhorando o desempenho econômico do país. Mais especificamente, deveria ser implementado um federalismo do tipo market-preserving (FMP).

Conforme este mesmo autor, são necessárias especificamente três condições para solucionar esse dilema estrutural de todo sistema federativo e se ter FMP: $i$ ) governos subnacionais devem ter a primazia na responsabilidade de provisão de bens públicos com autonomia tributária; entretanto, ii) esses governos devem enfrentar hard budget constraint, o que significa que eles devem suportar todas as consequências das suas políticas fiscais; e, iii) um mercado comum é assegurado, isto é, há livre mobilidade de fatores e bens no país.

Observa-se que no federalismo brasileiro, de maneira geral: i) o governo central detém o protagonismo político e econômico; ii) apesar dos avanços dos últimos anos da Lei de Responsabilidade Fiscal (LRF), estados e municípios ainda têm graus de liberdade para serem grandes e deficitários; ${ }^{7} \mathrm{e}$ iii) há relativa mobilidade de capital e trabalho dentro da fronteira federal, ou seja, não sem restrições.

Sendo assim, o objetivo central deste trabalho foi determinar se, atendidas determinadas condições do FMP no sistema federativo brasileiro, haverá ganhos econômicos para a nação. No caso do Brasil, significa implementar maior descentralização fiscal disciplinada pela imposição de restrição orçamentária rígida e livre mobilidade de fatores.

Vários trabalhos têm abordado o tema da descentralização no Brasil nos últimos anos, mas não sob a perspectiva explícita da teoria do FMP e sem empregar modelos de Equilíbrio Geral Computável (EGC). ${ }^{8}$ Dentro do campo de modelos EGC, Porsse (2005) estudou a controvérsia teórica sobre a importância da competição interjurisdicional na performance econômica para o caso brasileiro, mesmo que tomando somente o Rio Grande do Sul de forma desagregada e sem considerar aspectos mais gerais do federalismo.

Já trabalhos como o de Palermo et al. (2013) e Salami e Fochezatto (2009), usando modelos EGC, mostraram evidências de impactos favoráveis de política econômica ao realizarem simulações tributárias de cunho

7 Conforme amplamente divulgado, vários estados brasileiros enfrentam graves crises fiscais.

8 Por exemplo, Guedes e Gasparini (2007) e Martell (2008), dentre muitos outros. 
mais "institucionais" do que de redução de alíquotas, embora sem caráter "federativo", algo mais comum na literatura. ${ }^{9}$

Por último, destaca-se que testar para o Brasil a hipótese do FMP via simulações por EGC é algo relativamente novo. O uso de EGC na vasta literatura de federalismo ainda é tímido (Dixon et al. 2002, Nechyba 1996), sendo, no Brasil, quase que completamente inexistente. Além do que, testar a validade empírica da principal proposição teórica do FMP é, atualmente, a principal necessidade desse ramo da literatura de federalismo (Weingast 2014).

A principal contribuição deste estudo, portanto, é apresentar evidências quanto à importância da relação entre o nível de descentralização fiscal ou tipo de sistema federativo (particularmente o FMP) ou, de maneira mais geral, a estrutura institucional de um país e seu desempenho econômico usando um modelo EGC. Ainda como inovação, consideram-se as cinco grandes regiões brasileiras desagregadas com os seus respectivos governos regionais.

Para tanto, este artigo contém mais quatro seções, além desta introdução. Na próxima seção, procura-se apresentar o insight teórico capaz de explicar os problemas históricos do federalismo brasileiro. Na sequência, é apresentado o modelo PAEG Federal com a inclusão do governo descentralizado e variáveis de transferências de renda entre os agentes. ${ }^{10} \mathrm{Na}$ quarta seção, são discutidos os resultados encontrados e, por fim, conclui-se com algumas considerações finais e sugestões de políticas.

\section{Federalismo Fiscal Market-Preserving}

Para se obter um sistema federativo estável, de Figueiredo Jr. e Weingast (2005) afirmam que a implementação de descentralização fiscal tem de obedecer a dois pilares: a) o governo central deve ter instrumentos fortes o suficiente para deter e punir potenciais unidades subnacionais free-riders; e b) a necessidade de se ter restrições constitucionais ao governo central

9 Inclusive em Pereira (2011) usa-se o mesmo modelo deste artigo para se fazer simulações de reforma fiscal.

${ }^{10}$ O PAEG federal é uma variação do PAEG (Projeto de Análise da Equilíbrio Geral da Economia Brasileira) padrão. Em Teixeira et al. (2013) encontra-se toda a documentação do pacote composto de base de dados e modelo teórico e computacional. 
para que este não invada a autonomia e a independência política e fiscal das unidades subnacionais. A esse arranjo ideal denomina-se federalismo self-enforcing.

Não obstante, estes autores destacam que tornar o federalismo self-enforcing não é tarefa trivial porque implica resolver um trade-off fundamental: os mecanismos que mitigam um dilema tipicamente exacerbam outro. Um governo nacional muito fraco vai permitir comportamentos free-riding de unidades subnacionais. No limite, a federação será desintegrada. Por outro lado, com a União muito forte, a tendência de longo prazo é a federação também se dissolver porque o centro compromete a independência dos estados e municípios.

Assim, para Weingast (2005), todas as federações, embora distintas em inúmeros aspectos, enfrentam dois dilemas fundamentais: quais fatores previnem a dissolução do federalismo pelo governo federal por meio da centralização do poder e quais fatores impedem que as unidades subnacionais atuem como free-riders, exportando para toda a federação os equívocos de políticas fiscais. O modo como os diferentes arranjos institucionais da federação lidam com esses dilemas afeta os incentivos das várias esferas de governo, o que, por sua vez, influencia os desempenhos econômicos e a estabilidade do regime ao longo do tempo.

Particularmente, a questão tem sido colocada em termos de como um sistema federal pode ser market-preserving, ${ }^{11}$ isto é, capaz de estimular o aumento da atividade econômica consistentemente ao longo do tempo (Weingast 2014, Weingast 2009). Por conseguinte, um regime federal normalmente apresenta duas características básicas: a) estado hierárquico com ao menos duas esferas de governo sob a mesma terra e povo, com um escopo bem delineado de autoridade e autonomia; e b) a autonomia de cada governo é institucionalizada de maneira a tornar as restrições federativas self-enforcing.

Essas duas primeiras condições blindam preventivamente as investidas da União a favor da centralização ao longo do tempo. Alguma coisa precisa prover durabilidade aos limites do governo central, particularmente tornando essa opção atrativa para ele. Nessa perspectiva, a descentralização institucionalizada do poder em esferas menores de governo dificultaria intervenções excessivas do centro.

11 Ou federalismo market-enhancing. 
De fato, essas duas características cumprem um papel importante para tornar o sistema federativo viável, especialmente pelo fato de impedir intervenções interfederativas, particularmente da União contra os governos regionais, resolvendo, assim, uma das faces do dilema. Mas elas não dizem muita coisa sobre a autoridade e a jurisdição sobre determinados assuntos. Portanto, elas são condições necessárias, mas não suficientes, para se ter um federalismo que faça uma economia prosperar. $^{12}$

Assim, há um subconjunto de sistemas federativos denominados federalismo market-preserving (FMP). Um federalismo, que, conforme Weingast (2009), pertencerá a esse subconjunto se tiver as seguintes características adicionais: $i$ ) governos subnacionais devem ter primazia na responsabilidade de provisão de bens públicos e regulação da economia com a devida autonomia tributária para cumprir essas funções; entretanto ii) esferas inferiores de governo devem enfrentar hard budget constraint ou restrição orçamentária rígida, o que significa suportar todas as consequências das suas políticas fiscais e monetárias, impedindo as transferências dos prejuízos financeiros para outras unidades ou esferas de governos e gerações (via endividamento); e iii) um mercado comum é assegurado, impedindo que as unidades regionais usem de suas prerrogativas para impor barreiras comerciais contra insumos, bens e serviços de outras regiões, isto é, há livre mobilidade desses no território nacional.

Algumas dessas condições tornam explícita parte dos princípios implícitos no Federalismo Fiscal de Primeira Geração (FFPG), como os benefícios de eficiência advindos da descentralização (Oates 1972), competição interjurisdicional (Tiebout 1956) e o alinhamento de competências conforme características dos bens públicos (Musgrave 1959). Nesse sentido, o FMP estende e adapta as lições da FFPG para o contexto de políticos e burocratas racionais e sujeitos a incentivos. Essa perspectiva ajuda a identificar os incentivos gerados pelo tipo de estrutura institucional da descentralização, como o caso do Brasil, além de outras anomalias inerentes ao sistema federativo, como o efeito flypaper.

Desse modo, a literatura associada ao FMP afirma que governos subnacionais nos quais parte substancial das receitas é proveniente de recursos próprios tendem a ser mais transparentes para os cidadãos, a proverem os serviços públicos de forma mais eficiente, a fomentarem a atividade econô${ }^{12}$ A condição $a$ define um sistema federal de governo propriamente dito. A rigor, o Brasil atende a essas
duas condições, por isso serão tomadas como dadas neste trabalho. 
mica e a serem menos corruptos. Diferentemente, governos financeiramente dependentes estão sujeitos a maiores níveis de corrupção, à influência de grupos de pressão e à alocação ineficiente de recursos (Weingast 2014).

Ao mesmo tempo, há também a preocupação de que não haja instrumentos monetários disponíveis às esferas subnacionais, como emissão monetária ou empréstimos facilitados para cobertura de déficits fiscais, inclusive evitando salvamentos (bailouts) por parte da União. O objetivo é criar restrições orçamentárias rígidas e evitar comportamentos de carona (free-rider), uma vez que os salvamentos da União exportam os custos do endividamento para todos os estados, configurando um típico problema de recurso comum.

Quanto à livre mobilidade de fatores, ela introduz concorrência entre as unidades subnacionais por trabalho e capital. Restrições à União e responsabilidade quanto à regulação da economia nas jurisdições inferiores fazem com que estas unidades escolham ofertar bens públicos que favoreçam a atividade econômica e que estejam mais de acordo com a preferência dos cidadãos. E ainda, segundo Weingast (2009), há grande diminuição de perdas provenientes de atividades de rent-seeking e grupos de pressão porque a influência destes é somente no nível local, fazendo com que os grupos prejudicados possam se mover entre jurisdição.

Assim, o FMP tenderia a resolver os problemas de incentivos porque procura, na medida do possível, alinhar as decisões de gasto público e seu respectivo e estrito custo com as preferências dos cidadãos beneficiados, minimizando os problemas diversos de externalidades e consolidando a importância da mobilidade de fatores, melhorando o perfil fiscal de todo setor público e todas as consequências positivas na economia da nação advindas disso.

Em suma, o FMP defende que haja para as esferas de governos as mesmas três premissas que, geralmente, em condições normais, se procura estruturar para os agentes privados: autonomia de decisão (descentralização fiscal), responsabilidade financeira (restrição orçamentária rígida) e concorrência (mobilidade de fatores). 


\section{Modelo Analítico}

O Projeto de Análise de Equilíbrio Geral da Economia Brasileira (PAEG) é um modelo de equilibrio geral computável estático, global, multirregional e multissetorial, construído com vistas a analisar a economia brasileira de forma regional, sendo cada uma das cinco grandes regiões representada por uma estrutura de demanda intermediária e final, composta por setores selecionados e despesas públicas e privadas com bens e serviços (Teixeira et al. 2013). Ele está plenamente integrado ao modelo e base de dados do Global Trade Analysis Project (GTAP), versão 9, que inclui os fluxos de transações econômicas globais pela compatibilização de matrizes de insumo-produto (MIPs) nacionais..$^{13}$

O PAEG tem a estrutura básica do modelo GTAPinGAMS, criado originalmente por Rutherford (2010). O GTAPinGAMS foi elaborado como um problema de complementariedade não linear, em linguagem de programação GAMS (General Algebraic Modeling System).

Baseia-se, ainda, nas pressuposições microeconômicas neoclássicas para o comportamento dos agentes: o consumidor representativo busca otimizar seu bem-estar sujeito a uma restrição orçamentária, e o setor produtivo combina insumos intermediários e fatores primários, com vistas a minimizar os custos, dada a tecnologia. ${ }^{14}$

Por hipótese, as preferências são contínuas e convexas, das quais resultam funções de demanda contínuas e homogêneas de grau zero em relação aos preços, ou seja, somente os preços relativos podem ser determinados. Pelo lado das firmas, a tecnologia é representada por uma função de produção com rendimentos constantes de escala, significando que o lucro econômico das firmas é nulo no equilíbrio, agindo em mercados perfeitamente competitivos.

Dessa forma, podem-se enumerar três condições essenciais de consistências da base de dados: equilíbrio dos mercados (oferta igual à demanda para todos os bens e fatores); balanço da renda, isto é, renda líquida igual à despesa líquida para cada agente econômico; e, por último, a renda é exaurida pelas unidades produtivas, dado um conjunto de identidades que

${ }_{13}$ Para uma descrição completa do GTAP, ver Hertel (1997).

${ }^{14}$ As regras de fechamento microeconômicas e macroeconômicas do PAEG estão bem documentadas em Teixeira et al. (2013). 
se aplicam a cada um dos setores produtivos: lucro econômico igual a zero. Quanto às regras de fechamento macroeconômicas, a demanda de investimento e os fluxos de capitais internacionais são fixados exogenamente nos valores do ano base. Assim, mudanças na taxa real de câmbio ocorrem para acomodar alterações nos fluxos de exportações e importações após os choques, mantendo o saldo do balanço de pagamentos constante.

A dotação total de fatores de produção não se altera, mas estes são móveis entre setores. ${ }^{15}$ Há três tipos de mobilidade de fatores de produção no modelo utilizado: no primeiro caso, sem migração de fatores, os rendimentos de capital e trabalho se equalizam entre setores somente dentro da sua própria região de origem. No segundo tipo, denominada mobilidade imperfeita, ocorre a equalização da renda nominal dos fatores entre setores e regiões do Brasil. E, por último, mobilidade perfeita de fatores com equalização dos rendimentos reais entre setores e regiões brasileiras. ${ }^{16}$ Como não há desemprego de fatores e os preços são flexíveis, opera-se em pleno emprego.

Desse modo, considera-se estritamente uma economia pela sua ótica produtiva ou real, desconsiderando, portanto, aspectos monetários e financeiros. Como o investimento é fixo, portanto, sem acumulação de capital, e não há um fluxo endógeno de renda líquida de fatores externos pela conta financeira no balanço de pagamentos, não se faz inferências de trajetória de crescimento do Produto Interno Bruto (PIB) no modelo.

Nos trabalhos de Teixeira et al. (2013), Pereira (2011), Gurgel (2002), Rutherford (1999) e Hertel (1997) tem-se a exposição completa das equações comportamentais e de equilíbrio do modelo base do PAEG e das suas fontes originárias: GTAP e GTAPinGAMS.

15 Assume-se que capital é divisível entre setores e regiões brasileiras. Vale destacar que não há migração de fatores entre o Brasil e as demais regiões do modelo.

${ }^{16}$ Considerando que não há parâmetros regionais bem definidos que permitam estabelecer diferentes níveis de restrições ou propensões à mobilidade entre as regiões brasileiras no modelo de EGC, o modelo computacional do PAEG de equilíbrio geral considera essas três regras de mobilidade (logo, uma das hipóteses implícitas é de que elas são as mesmas para cada uma das cinco regiões do país). Contudo, como os resultados para as duas últimas regras foram muito próximos, por ser a segunda regra mais realista que a terceira, e também para diminuir a combinação das três características do FMP a serem simuladas sem perdas para análise, optou-se por usar somente as duas primeiras regras neste artigo como será visto mais adiante. 
Contudo, como no PAEG padrão o agente governo é único em cada região, foi necessário desmembrá-lo na base de dados em governo federal (GF) e governos regionais (GR), para as cinco grandes regiões brasileiras, modelando-os separadamente para permitir as simulações e as análises pretendidas. Além disso, com vistas a refinar o padrão de gastos desses agentes, tornando a modelagem mais realista, foram incluídos na matriz diferentes mecanismos e valores de transferência de renda entre governos e famílias. ${ }^{17}$

Dessa forma, foram feitas alterações nas equações do modelo econômico correspondente: introdução das receitas e despesas das esferas de governos separadamente nas identidades contábeis e condições de lucro zero e incorporação das variáveis de transferência de renda nas equações de restrição orçamentária do agente privado e dos dois governos.

Segue abaixo a descrição do modelo com suas principais equações e extensões implementadas para o caso das cinco regiões brasileiras, o que o torna, na verdade, numa variação do PAEG original. O modelo aqui utilizado é denominado de PAEG Federal.

\subsection{Modelo PAEG Federal}

O Quadro 1 apresenta a notação para as dimensões do modelo, incluindo os conjuntos de setores, países e regiões, fatores de produção e governos. Vale destacar, mais uma vez, que a divisão em dois governos e a inclusão de variáveis de transferência de renda ocorrem somente para as regiões brasileiras. Em todas as demais, o modelo retoma sua forma original.

Quadro 1 - Indices de conjuntos da base de dados

\begin{tabular}{|c|l|}
\hline Índice & \multicolumn{1}{|c|}{ Descrição } \\
\hline $\mathrm{i}, \mathrm{j}$ & Setores \\
\hline $\mathrm{r}, \mathrm{s}$ & Países ou regiões \\
\hline $\mathrm{g}$ & Esferas de governo (federal e regional) \\
\hline $\mathrm{f}$ & Fatores de produção (capital e trabalho) \\
\hline
\end{tabular}

Fonte: Adaptado de Teixeira et al. (2013).

${ }^{17}$ As demais regiões do modelo global permanecendo com um único governo e apenas com um fluxo de transferências líquidas entre setor público e famílias, mantendo, assim, para essas regiões todas as identidades e regras de comportamento iguais ao modelo base descrito em Teixeira et al. (2013). 


\subsubsection{Funções de Identidade: equilibrio no mercado de bens e fatores}

A primeira função de identidade é mostrada na equação (1): a soma das exportações $\left(v x m d_{i r s}\right)$, do serviço de transporte internacional ( $\left.v s t_{i r}\right)$, da demanda intermediária $\left(v d f m_{i j r}\right)$, do consumo das famílias $\left(v d p m_{i r}\right)$, dos investimentos $\left(v \mathrm{dim}_{i r}\right)$ e do consumo do governo $\left(v d g m_{\text {irg }}\right)$, onde $g$ indica o tipo de governo, ${ }^{18}$ realizados no mercado de bens e serviços domésticos é necessariamente igual ao valor do produto agregado doméstico $\left(\right.$ vom $\left._{i r}\right)$ :

$v^{0} m_{i r}=\sum_{s} v x m d_{i r s}+v s t_{i r}+\sum_{j} v d f m_{i j r}+v d p m_{i r}+v d i m_{i r}+v d g m_{i r g}$

Da mesma forma, a demanda agregada por bens importados (vim ir ) obtêm seu valor: do somatório da demanda intermediária dos setores domésticos $\left(\right.$ vifm $\left._{\text {jir }}\right)$, consumo privado $\left(\right.$ vipm $\left._{\text {ir }}\right)$, investimentos $\left(\right.$ viim $\left._{\text {ir }}\right)$ e consumo do governo $\left(\right.$ vigm $\left._{\text {irg }}\right)$, mais uma vez indexado por $g$. Então, a identidade contábil para esse fluxo é:

$$
\operatorname{vim}_{i r}=\sum_{j} v_{i f m_{i j r}}+\operatorname{vipm}_{i r}+\operatorname{viim}_{i r}+\operatorname{vigm}_{i r g}
$$

O equilíbrio no mercado de fatores é dado pela identidade relacionando a soma da demanda intermediária por fatores primários com renda destinada as famílias $\left(\right.$ evom $\left._{f r}\right)$ :

$$
\sum_{i} v f m_{f i r}=e v o m_{f r}
$$

De forma semelhante, as condições de equilíbrio do mercado internacional requerem que a região $r$ exporte o bem $i\left(v x m_{i r}\right)$ na mesma quantidade que a soma das importações do mesmo bem de todos os parceiros comerciais $\left(v x m d_{\text {irs }}\right)$ :

$$
v x m_{i r}=\sum_{s} v x m d_{i r s}
$$

Tal qual as condições de equilíbrio se aplicam para os serviços de transporte internacional. O equilíbrio no mercado de serviço de transporte $j$ requer que a soma dos serviços para a exportação de todas as regiões (vst $t_{i r}$ ) iguale a soma de todos os fluxos bilaterais de serviços de transportes adquiridos nas importações de bens $\left(v t w r_{j i r s}\right)$. Dito de outra forma, o valor das margens de comércio internacional deve ser igual tanto ao serviço

${ }^{18}$ Se $r \in$ (Brasil) para essa e as próximas equações. 
de transporte internacional, quanto ao valor das vendas internacionais de transporte:

$$
\sum_{r} v s t_{r j}=\sum_{i s r} v t w r_{j i r s}
$$

Assim, tem-se o equilíbrio entre oferta e demanda em todos os mercados atendendo uma das condições para consistência do modelo de equilíbrio geral com uma matriz de dados.

\subsubsection{Equações de Restrição Orçamentária: balanço da renda}

A nova restrição orçamentária do agente privado no modelo PAEG Federal tem do lado esquerdo a renda dos fatores de produção $\left(\right.$ evom $\left._{f r}\right)$, descontados os pagamentos de impostos $\left(R_{r g}^{H H}\right)$ e contribuições sociais pagos aos dois governos $\left(\mathrm{CS}_{r g}^{\mathrm{HH}}\right)$, e somados o recebimento líquido de juros $\left(J R_{r g}^{H H}\right)$ e benefícios sociais $\left(B S_{r g}^{H H}\right)$ também dos dois governos, além de uma variável de transferência de renda entre famílias e governos regionais $\left(\operatorname{tau}_{r}^{G R}\right)$, que poderá ser positiva ou negativa dependendo do choque simulado. ${ }^{19}$ Do lado direito tem-se as despesas de consumo final $\left(v p m_{r}\right)$ e investimento $\left(\mathrm{vim}_{r}\right)$ :

$$
e^{2 v o m_{f r}}-R_{r g}^{H H}-C S_{r g}^{H H}+J R_{r g}^{H H}+B S_{r g}^{H H}+t a u_{r}^{G R}=v p m_{r}+v i m_{r}
$$

Quanto ao governo, tem-se agora nesta variação do modelo PAEG duas equações de restrição orçamentária, uma para a União e outra para o governo regional. No caso federal (representado pelo sobrescrito GF), a despesa pública total $\left(v g m_{r}^{G F}\right)$ tem que ser igual aos fluxos federais de impostos (representado pelo índice " $F$ ") indiretos na produção e exportação $\left(R_{i r F}^{Y}\right)$, no consumo da família representativa $\left(R_{r F}^{C}\right)$, nas importações $\left(R_{i r F}^{M}\right)$, na demanda do governo federal $\left(R_{r F}^{G F}\right)$ e governo regional $\left(R_{r F}^{G R}\right)$ e sobre os fatores $\left(R_{r F}^{H H}\right)$. A renda do governo federal também inclui os recebimentos das contribuições sociais $\left(C S_{r F}^{H H}\right)$ menos os pagamentos de benefícios sociais $\left(B S_{r F}^{H H}\right)$ às famílias, pagamentos líquidos de juros $\left(J R_{r F}^{H H}\right)$ e transferências líquidas aos governos regionais $\left(T R_{r F}^{G R}\right)$, bem como transferência do exterior $\left(v b_{r}^{G F}\right)$. Tanto no PAEG padrão como no Federal, $v b_{r}^{G F}$ é absorvido pelo governo federal conforme resultado externo do país. Então, a equação de restrição toma o seguinte formato:

${ }^{19}$ Mais detalhes sobre essa variável logo adiante. 
$v g m_{r}^{G F}=\sum_{i} R_{i r F}^{Y}+R_{r F}^{C}+\sum_{i} R_{i r F}^{M}+R_{r F}^{G F}+R_{r F}^{G R}+R_{r F}^{H H}+C S_{r F}^{H H}-B S_{r F}^{H H}-J R_{r F}^{H H}-T R_{r F}^{G R}+v b_{r}^{G F}(7)$

A restrição orçamentária do governo regional é definida de maneira análoga com basicamente uma diferença: retira-se $v b_{r}^{G F}$ incluindo o $t a u_{r}^{G R}$ (responsável pela transferência de renda entre famílias e GRs). Assim, a despesa pública total regional $\left(v g m_{r}^{G R}\right)$ tem que ser igual à arrecadação de impostos (representado pelo índice " $R$ ") indiretos na produção e exportação $\left(R_{i r F}^{Y}\right)$, no consumo $\left(R_{r R}^{C}\right)$, nas importações $\left(R_{i r R}^{M}\right)$, na demanda do governo federal $\left(R_{r R}^{G F}\right)$ e governo regional $\left(R_{r R}^{G R}\right)$ e sobre os fatores $\left(R_{r R}^{H H}\right)$. A renda dos governos regionais inclui ainda os recebimentos das contribuições sociais $\left(C S_{r R}^{H H}\right)$ menos pagamento de benefícios sociais $\left(B S_{r R}^{H H}\right)$ às famílias, pagamentos líquidos de juros $\left(J R_{r R}^{H H}\right)$ e recebimentos líquidos de transferências da União $\left(T R_{r R}^{G F}\right),{ }^{20}$ além da variável de transferência de renda entre famílias e governos regionais $\left(\operatorname{tau}_{r}^{G R}\right)$ definida antes. Logo, a equação de restrição toma a seguinte forma:

$v g m_{r}^{G R}=\sum_{i} R_{i r R}^{Y}+R_{r R}^{C}+\sum_{i} R_{i r R}^{M}+R_{r R}^{G F}+R_{r R}^{G R}+R_{r R}^{H H}+C S_{r R}^{H H}-B S_{r R}^{H H}-J R_{r R}^{H H}-T R_{r R}^{G F}+t a u_{r}^{G R}$

Considerando que a consistência do modelo exige que variações nas receitas dos agentes (despesas) devem ser compensadas por alterações equivalentes em suas despesas (receitas), vale mencionar que as simulações de superávit (déficit) dos governos regionais previstas neste trabalho foram implementadas por meio da variável tau que transfere (recebe) recursos destes para as famílias. Na prática, diminuiu-se (aumentou-se) o tamanho desses governos na economia. Tomou-se esse artifício como uma estimativa das mudanças (simuladas) nas necessidades de financiamento dos governos e, por conseguinte, as variações exigidas na tributação e/ou compra/venda de títulos junto às famílias. ${ }^{21}$

Em vista disso, atende-se, no modelo construído, a segunda condição para a consistência da base de dados, qual seja: o balanço da renda dos agentes.

20 Onde $\left|J R_{r g}^{H H}\right|=\left|J R_{r F}^{H H}\right|+\left|J R_{r R}^{H H}\right|$ e $\left|T R_{r F}^{G R}\right|=\left|T R_{r R}^{G F}\right|$.

${ }^{21}$ Uma espécie de antecipaçấo das açốes previstas na "equivalência ricardiana", segundo a qual os contribuintes atuais consideram que o endividamento do governo, como mecanismo de financiamento dos seus gastos, é equivalente à elevação de impostos para as gerações futuras. 


\subsubsection{Condições de Lucro Zero}

Por fim, há no modelo um terceiro conjunto de identidades, conforme Equações (9) a (16), que mostra como a renda é exaurida por cada umas das "unidades produtivas", correspondendo à terceira condição de consistência da base de dados: lucros operacionais líquidos iguais a zero. Dito de outra forma, os custos com insumos intermediários e fatores de produção se igualam ao valor da produção, dado que se supõe competição perfeita e retornos constantes à escala:

$$
\begin{aligned}
& Y_{i r}: \sum_{f} v f_{f i r}+\sum_{j}\left(v i f m_{j i r}+v d f m_{j i r}\right)+R_{i r g}^{Y}=v o m_{i r} \\
& M_{i r}: \sum_{s}\left(v x m d_{i s r}+\sum_{j} v t w r_{j i s r}\right)+R_{i r g}^{M}=v i m_{i r} \\
& C_{r}: \sum_{i}\left(v d p m_{i r}+v_{i p m_{i r}}\right)+R_{i r g}^{C}=v p m_{r} \\
& G F_{r}: \sum_{i}\left(v d g m_{i r F}+v_{i g m_{i r F}}\right)+R_{i r g}^{G F}=v g m_{r F} \\
& G R_{r}: \sum_{i}\left(v d g m_{i r R}+v i g m_{i R}\right)+R_{i r g}^{G R}=v g m_{r R} \\
& I_{r}: \sum_{i} v \operatorname{dim}_{i r}=v i m_{r} \\
& F T_{f r}: \text { evom }_{f r}=\sum_{i} v f m_{f i r} \\
& Y T_{j}: \sum_{r} v s t_{j r}=v t_{j}=\sum_{i r s} v t w r_{j i r s}
\end{aligned}
$$

Assim, as equações apresentadas indicam presença de equilíbrio de mercado para todos os bens e fatores, balanço da renda dos agentes econômicos e a existência das condições de lucro zero, conforme as pressuposições que definem o modelo.

\subsubsection{Estrutura de Decisão do Modelo}

Como assinalado por Fochezatto (2003), a construção de um modelo de equilíbrio geral computável inclui a atribuição de formas funcionais aos agentes econômicos que representem o seu comportamento na geração dos fluxos de receitas e despesas da matriz de dados. A finalidade é que os valores expressos nestes fluxos resultem das ações comportamentais ótimas dos agentes do modelo. 
Desse modo, a estrutura dos problemas de otimização de cada agente, as respectivas árvores tecnológicas de decisão e as equações derivadas das condições de equilíbrio deste trabalho são baseadas nas do modelo PAEG padrão, exceto pela adição do índice g nas variáveis de impostos, indicando desmembramento em dois tipos de governo para cada região. Ademais, cabe ressaltar que todos os parâmetros de elasticidades de substituição em cada nível de escolha das árvores tecnológicas foram retirados da base de dados do GTAP versão $9 .^{22}$

De todo modo, apresenta-se a seguir o programa de otimização da família representativa a fim de exemplificar este ponto. Os Quadros 2, 3 e 4, abaixo, resumem a notação usada no modelo exibindo a equivalência entre as variáveis econômicas com o código do GAMS. O Quadro 2 mostra as variáveis endógenas que tem seus valores determinados no equilíbrio.

O Quadro 3 apresenta os impostos, os subsídios e as tarifas incidentes no modelo, com seus respectivos parâmetros e notação em GAMS. E, por fim, o Quadro 4 define os preços relativos dos bens e fatores. As condições de equilíbrio determinam preços relativos.

Quadro 2 - Variáveis de atividade que obtém seus valores ótimos no equilíbrio

\begin{tabular}{|c|l|}
\hline Variáveis & \\
\hline$Y_{i r}$ & Produção de bens e serviços \\
\hline$M_{i r}$ & Importações agregão \\
\hline$C_{r}$ & Demandas das famílias \\
\hline$G F_{r}$ & Demanda do governo federal \\
\hline$G R_{r}$ & Demanda do governo regional \\
\hline$F T_{f r}$ & Transformações de fatores \\
\hline$Y T_{j}$ & Serviços de transporte internacional \\
\hline
\end{tabular}

Fonte: Adaptado de Pereira (2011).

${ }^{22}$ Ver Aguiar et al. (2016). 
Quadro 3 - Impostos, tarifas e subsídios do modelo ${ }^{23}$

\begin{tabular}{|l|c|c|}
\hline \multicolumn{1}{|c|}{ Descrição das Alíquotas } & Notação & Parâmetro GAMS \\
\hline Imposto sobre o produto & $t_{i r F}^{o}+t_{i r R}^{o}=t_{i r}^{o}$ & $r t_{i r g}$ \\
\hline Imposto sobre os fatores de produção & $t_{f j r F}^{f}+t_{f j r R}^{f}=t_{f j r}^{f}$ & $r t f_{f r g}$ \\
\hline Imposto sobre insumos intermediários domésticos & $t_{i j r F}^{f d}+t_{i j r R}^{f d}=t_{f j r}^{f d}$ & $r t f d_{i j r g}$ \\
\hline Imposto sobre insumos intermediários importados & $t_{i j r F}^{f i}+t_{i j r R}^{f i}=t_{i j r}^{f i}$ & $r t f i_{i j r g}$ \\
\hline Imposto sobre o consumo doméstico & $t_{i r F}^{p d}+t_{i r R}^{p d}=t_{i r}^{p d}$ & $r t p d_{i r g}$ \\
\hline Imposto sobre o consumo importado & $t_{i r F}^{p i}+t_{i r R}^{p i}=t_{i r}^{p i}$ & $r t p i_{i r g}$ \\
\hline Subsídios à exportação & $t_{i s r F}^{x s}+t_{i s r R}^{x s}=t_{i s r}^{x s}$ & $r t x s_{i s r g}$ \\
\hline Tarifas à importação & $t_{i s r F}^{m s}+t_{i s r R}^{m s}=t_{i s r}^{m s}$ & $r t m s_{i s r g}$ \\
\hline
\end{tabular}

Fonte: Adaptado de Pereira (2011).

Quadro 4 - Preços relativos de bens e fatores

\begin{tabular}{|c|l|c|}
\hline Notação & \multicolumn{1}{|c|}{ Descrição } & Parâmetro \\
\hline$p_{r}^{C}$ & Índice de preço do consumo & $p c_{r}$ \\
\hline$p_{r}^{G F}$ & Índice de preço dos gastos públicos federais & $p g F_{r}$ \\
\hline$p_{r}^{G R}$ & Índice de preço dos gastos públicos regionais & $p g R_{r}$ \\
\hline$p_{i r}^{Y}$ & Preço de oferta, bruto de impostos indiretos à produção & $p y_{i r}$ \\
\hline$p_{i r}^{M}$ & Preço das importações, bruto de imposto às exportações e tarifas & $p m_{i r}$ \\
\hline$p_{j}^{T}$ & Custo marginal de serviços de transportes & $p t_{j}$ \\
\hline$p_{i r}^{f}$ & Preço do fator primário & $p f_{f i r}$ \\
\hline
\end{tabular}

Fonte: Adaptado de Pereira (2011).

Assim, o consumo da família representativa consistente com a maximização de utilidade é retratado pela minimização dos custos, dado um nível de consumo agregado, em que a família representativa decide sobre os bens e serviços domésticos e importados ótimos:

${ }^{23} \mathrm{Na}$ subseção seguinte é mostrado como se deu a equivalência com os dados tributários. 
$\min _{d d p m, d i p m} p y_{i r}\left(1+t_{i r}^{p d}\right) d d p m_{i r}+p m_{i r}\left(1+t_{i r}^{p i}\right) d i p m_{i r u}$

Sujeito a.: $U_{r}($ ddpm, dipm $)=C_{\text {ir }}$

$\mathcal{L}=p y_{i r}\left(1+t_{i r}^{p d}\right) d d p m_{i r}+p m_{i r}\left(1+t_{i r}^{p i}\right) d i g m_{i r u}-\lambda\left(U_{r}(d d p m, \operatorname{dipm})-C_{i r}\right)$

CPOs:

$\frac{\partial \mathcal{L}}{\partial d d p m}=0 \Rightarrow \lambda=\frac{p y_{i r}\left(1+t_{i r}^{p d}\right)}{U M g_{d d p m}} ; \quad \quad p y_{i r}\left(1+t_{i r}^{p d}\right)=p_{d d p m}$

$\frac{\partial \mathcal{L}}{\partial \text { dipm }}=0 \Rightarrow \lambda=\frac{p m_{\text {ir }}\left(1+t_{\text {ir }}^{p i}\right)}{U M g_{\text {dipm }}} ; \quad \quad p m_{\text {ir }}\left(1+t_{\text {ir }}^{p i}\right)=p_{\text {dipm }}$

assim:

$\frac{U M g_{d d p m}}{U M g_{\text {dipm }}}=\frac{p_{d d p m}}{p_{\text {dipm }}}$

Logo, considerando as identidades para os impostos desagregados em duas esferas de governo conforme Tabela 3 , tem-se que a descentralização implementada não altera a condição de equilíbrio, sendo esse resultado análogo para os demais agentes do modelo. A estrutura de tributação indireta e direta das firmas e das famílias continuam as mesmas, alterando somente a distribuição dos recursos entre duas esferas de governo e, após os choques, os volumes arrecadados. Vale lembrar que no PAEG padrão a arrecadação tributária se destina unicamente a um governo hipotético em cada região.

Desse modo, os choques de descentralização implementados, conforme abordagem proposta dado as possibilidades do modelo utilizado, impactam a cesta ótima de bens e serviços escolhida por duas formas, podendo, portanto, atingir curvas de indiferença maiores ou menores: (1) deslocamentos da restrição orçamentária (RO) por meio de alterações de renda dos agentes; e (2) mudanças na inclinação da RO mediante variações nos preços relativos devido à modificação no volume de gastos dos agentes, ocorrendo simultaneamente e conforme o encadeamento intersetorial e de transferência de renda da matriz de dados. 


\subsection{Cálculo do Bem-estar e PIB}

A proxy para verificar os ganhos de bem-estar na economia brasileira em função das simulações previstas neste trabalho foi a medida de variação equivalente, que tem sido comumente utilizada para mensuração de ganhos de bem-estar em modelos aplicados de equilíbrio geral, particularmente pelos trabalhos que usam o PAEG. ${ }^{24}$ As mudanças nos níveis de bem-estar auferidas pelo conceito de variação equivalente, expressa em termos percentual e monetário, reflete as consequências de diversas mudanças na produção, fluxos comerciais e preços da economia. Ela pode ser calculada da seguinte forma:

$$
V E=\frac{\left(U^{f}-U^{0}\right)}{U^{0}} C^{0}
$$

em que $V E$ representa a variação equivalente, $U^{f}$ representa o nível de utilidade final, $U^{0}$ retrata o nível de utilidade inicial e $C^{0}$ descreve a renda das famílias no equilíbrio inicial. Assim, a medida de variação equivalente reflete a mudança no consumo necessário, a partir de um novo conjunto de preços, para que se mantenha o mesmo nível de utilidade das famílias, aos preços do equilíbrio inicial. Então, aumento da utilidade em termos de aumento do consumo. Ela indica aumentos de bem-estar para valores positivos e queda de bem-estar para valores negativos.

Por isso, a possível elevação do bem-estar em virtude de choques no modelo representará ganhos diretos para as famílias em termos de aumento de renda para consumir mais e, portanto, ganhos de utilidade.

Quanto ao Produto Interno Bruto (PIB), o cálculo no modelo é realizado pela ótica da despesa, por meio da conhecida expressão:

$$
Y=C+I+G+X-M
$$

sendo que Y representa o PIB; C, o consumo privado; I, os investimentos; $\mathrm{G}$, os gastos do governo; $\mathrm{X}$, as exportações; e $\mathrm{M}$, as importações para o ano de 2011.

${ }^{24}$ Ver Pereira (2011) e Gurgel (2002), principalmente. 


\subsection{Base de Dados}

O modelo PAEG Federal utilizou a base de dados regionalizada para a economia brasileira, compatível com o GTAP 9.0. A agregação do PAEG 4.0, a mais nova versão do banco de dados, é composta por 19 atividades, 12 regiões (incluídas as 5 grandes regiões brasileiras) e 2 fatores primários, representando o ambiente econômico de 2011, sendo que para cada região há os dados de um único governo para consumo público e receitas de impostos.

Assim sendo, as despesas públicas e as receitas tributárias foram desagregadas em federais e regionais, no intuito de simular o regime federativo de governo no modelo. Este procedimento foi feito com base nos diversos relatórios de finanças públicas de todo o setor governamental para o ano de 2011, divulgados pela Secretaria do Tesouro Nacional (STN) e pelo Instituto Brasileiro de Geografia e Estatística (IBGE). É importante observar que a desagregação manteve um nível regional de governo no sentido de as informações para estados e municípios dentro de cada grande região estarem agregadas. ${ }^{25}$

Os impostos, subsídios e tarifas para o Brasil nas matrizes regionais seguiram o padrão exposto na Quadro 3, desagregados pelo tributo específico que compõe cada categoria com as seguintes especificações, revistas e ampliadas por Pereira (2011): ${ }^{26}$

a) Imposto sobre o produto: contribuições sociais e econômicas e demais receitas e subsídios sobre atividades;

b) Imposto sobre os fatores de produção: IRPF, IRPJ, IOF, IPTU e ITR;

c) Imposto sobre insumos intermediários domésticos: ICMS, IPI, ISS e outros;

d) Imposto sobre insumos intermediários importados: II, IPI (vinculado às importações);

e) Imposto sobre o consumo doméstico: ICMS, IPI, ISS e outros impostos nacionais;

25 Os trabalhos de Palermo et al. (2013) e Porsse (2005) utilizam o mesmo procedimento de agrupamento dos dados dos estados e municípios num mesmo agente, também chamando-o de governo regional na matriz de contabilidade social.

${ }^{26}$ A metodologia completa da forma de obtenção das alíquotas dos impostos regionalizados encontra-se em Pereira (2011). 
f) Imposto sobre o consumo importado: II, IPI (vinculado às importações); e

g) Subsídios à exportação e tarifas à importação.

No Quadro 5 consta a distribuição de tributos conforme praticado atualmente no Brasil.

Quadro 5 - Distribuição de tributos por esferas de governo

\begin{tabular}{|c|l|}
\hline Esfera de Governo & \multicolumn{1}{c|}{ Descrição do Tributo } \\
\hline Central & IR; ITR; IPI; II; IE; IOF; Contribuições Sociais e Econômicas ${ }^{\star}$ \\
\hline Regional & ICMS; IPVA; ITCMD; IPTU; ISS e ITB|** \\
\hline
\end{tabular}

Fonte: Elaborado pelo autores.

* Imposto de Renda, Imposto sobre a Propriedade Territorial Rural, Imposto sobre Produtos Industrializados, Imposto de Importação, Imposto de Exportação, e Imposto sobre Operações de Crédito, Câmbio e Seguros.

** Imposto sobre Circulação de Mercadorias e Prestação de Serviços, Imposto sobre a Propriedade de Veículos Automotores, Imposto de Transmissão Causa Mortis e Doação, Imposto Predial e Territorial Urbano, Imposto sobre Serviço de Qualquer Natureza e Imposto de Transmissão de Bens Imóveis Inter-Vivos.

Além disso, foram incluídas as variáveis de transferências de renda entre os agentes do sistema econômico, tornando-a tipicamente uma Matriz de Contabilidade Social, ${ }^{27}$ compatível com as informações agregadas oficiais das Contas Econômicas Integradas publicadas pelo IBGE com vistas a refinar o padrão de gasto dos governos e tornar a modelagem mais realista.

O código padrão do modelo PAEG, escrito em MPSGE, também sofreu modificações com o objetivo de adaptá-lo aos novos dados e aos choques requeridos. ${ }^{28} \mathrm{O}$ Mathematical Programming System for General Equilibrium (MPSGE), desenvolvido por Thomas Rutherford (Rutherford, 1999), é uma linguagem de programação desenvolvida para solucionar modelos econômicos de equilíbrio do tipo Arrow-Debreu. O MPSGE usa como interface a linguagem de programação do GAMS.

${ }^{27}$ Para uma revisão de conceitos de Matrizes de Contabilidade Social, ver Feijó e Ramos (2013), entre muitos outros.

${ }^{28}$ A matriz de dados completa e o código em GAMS do modelo PAEG Federal estão disponíveis para consulta. 


\subsection{Exercícios de Simulação}

Foram definidos dois níveis representativos de intensidade para cada uma das três condições a serem implementadas. Logo, têm-se 8 combinações possíveis de cenários, sendo que o último deles é o Federalismo Marketpreserving (FMP). Decidiu-se por somente dois níveis de intensidade para não aumentar demasiadamente o número de cenários possíveis. No caso de três níveis para cada condição, por exemplo, ter-se-iam 27 cenários possíveis. $^{29}$

Quanto aos cenários, eles estão descritos no Quadro 6. Para a descentralização fiscal no nível 1 simplesmente manteve-se a distribuição atual ou vigente de arrecadação tributária e transferências entre esferas governos presentes na base de dados (nível denominado "baixo"). E o que se tem é uma participação de $52 \%$ do governo central e, por conseguinte, de $48 \%$ dos governos regionais no total de tributos. E 40\% em média das receitas totais dos governos regionais são provenientes de transferências recebidas da União.

Para o nível 2 implementou-se efetivamente descentralização fiscal: definiu-se que a participação nos tributos do governo federal (GF) passaria ser de 30\% e dos governos regionais (GRs) de 70\%, tendo como referência a mesma fatia de divisão da demanda final do setor público na base dados. Além disso, reduziu-se em 50 p.p. o volume de transferências intergovernamentais do GF para os GRs (nível denominado "alto"), o que significaria uma queda para $20 \%$ em média da participação dessas receitas no total regional.

Para a restrição orçamentária, os níveis de resultado fiscal obtidos via simulações materializam nas reações dos governos regionais condições de incentivos institucionais no ambiente político-econômico: regras orçamentárias críveis, baixa probabilidade de resgastes financeiros, condições políticas etc. Sendo assim, restrição orçamentária frouxa consistiu numa permissão para que os governos regionais incorressem em déficits fiscais da ordem de $1,6 \%$ do PIB e restrição orçamentária rígida correspondendo à obrigação de entregarem superávit de 1,6\% do PIB. Dentro do modelo construído, isso seria equivalente a um aumento e redução de $10 \%$ do ta-

${ }^{29}$ Testes com mais níveis foram realizados e não alteraram a direção e, portanto, as evidências dos resultados. 
manho desses governos na economia, respectivamente, via transferências ou recebimentos de recursos para/ou das famílias. ${ }^{30}$

Quadro 6 - Graus de intensidade das condições simuladas nos cenários analisados

\section{Descentralização Fiscal (DF)}

1-Baixa: sem alteração na distribuição orçamentária entre esferas de governo.

2-Alta: GF $30 \%$ e GRs $70 \%$ dos impostos e redução em 50 p.p. das transf. do GF aos GRs.

Restrição Orçamentária (RO)

1- Frouxa: aumento de $10 \%$ dos GRs na economia (equivalente a déficit de 1,6\% do PIB).

2- Rígida: redução de $10 \%$ dos GRs na economia (equivalente a superávit de $1,6 \%$ do PIB).

\section{Mobilidade de Fatores (MF)}

1- Intra-regional: mobilidade padrão PAEG (entre setores somente dentro da região).

2-Inter-regional: mobilidade entre regiões brasileiras até equalização de preços nominais.

Fonte: Elaborado pelos autores.

*governo federal (GF) e governos regionais (GRs). ${ }^{* *}$ Lembrando que "se tomou este artifício como uma estimativa das mudanças (simuladas) nas necessidades de financiamento dos governos e, por conseguinte, das variações exigidas na tributação e/ou compra/venda de títulos junto as famílias. "

Por fim, a mobilidade de fatores no nível 1 considerou a mobilidade na qual as famílias após os choques podem alocar capital e trabalho considerando variações reais nos seus preços somente entre setores da economia dentro da sua própria região, não podendo, portanto, migrar de região (denominado "intra-regional"). Por outro lado, no nível 2 (denominado "inter-regional") retira-se essa restrição permitindo a migração entre setores e regiões, embora com ajustamento via variações nos preços nominais dos fatores, até que as remunerações nominais se igualem entre regiões.

Quanto às suposições acerca da mobilidade, salienta-se que as restrições na migração de fatores aqui considerados entre as regiões brasileiras procuram captar basicamente restrições de cunho familiar, cultural, geográfico, tecnológico e financeiro, embora não havendo, no mundo real, empecilhos legais para a livre mobilidade de fatores no território nacional sob um regime federal de governo. Ressalta-se que a possibilidade de mobilidade de fatores dentro do território nacional é uma das características marcantes de todo sistema federativo.

\footnotetext{
${ }^{30}$ Considerando que a participação dos governos regionais no PIB é de $16 \%$ na base de dados.
} 
O Quadro 7 resume a ordem e o tipo de cada um dos cenários principais que foram usados como referência para apresentação dos resultados.

Quadro 7 - Cenários simulados

\begin{tabular}{cccc}
\hline Cenários & Descentralização Fiscal & Restrição Orçamentária & Mobilidade de Fatores \\
\hline 1 & baixa & frouxa & intra-regional \\
2 & baixa & rígida & intra-regional \\
3 & alta & frouxa & intra-regional \\
4 & alta & rígida & intra-regional \\
5 & baixa & frouxa & inter-regional \\
6 & baixa & rígida & inter-regional \\
7 & alta & frouxa & inter-regional \\
$8^{*}$ & alta & rígida & inter-regional \\
\hline
\end{tabular}

Fonte: Elaborado pelos autores.

* Cenário que simula o mais alto grau do federalismo fiscal market-preserving neste trabalho.

\section{Resultados e Discussão}

Os resultados para as 8 (oito) simulações ou choques no equilíbrio inicial da economia brasileira para o ano de 2011 são apresentados a seguir. A Tabela 1 mostra os resultados para os cenários 1 e 2 . O que há de comum nesses cenários é que não há alteração na distribuição orçamentária dos governos $^{31}$ (descentralização fiscal baixa) e a presença de mobilidade de fatores intra-regional, isto é, migração de capital e trabalho restrita aos setores de uma mesma região. O que os diferencia é a restrição orçamentária frouxa no primeiro caso e rígida no segundo. Em termos institucionais, como visto antes, o cenário 1 seria o pior arranjo para se estabelecer no país.

De fato, o exercício contrafactual corrobora a sugestão teórica: nota-se que no cenário 1 o bem-estar e o PIB de todas as regiões caem, sendo que no agregado essas variações negativas foram da ordem de $-2,21 \%$ e $-0,001 \%$, as maiores quedas de todos os cenários. A evidência é de uma piora generalizada da economia em função da concentração fiscal, de governos regionais

${ }^{31}$ Maior parcela da arrecadação tributária nas mãos do Governo Federal e dependência financeiras das unidades regionais de transferências da União. 
maiores e restrições na mobilidade de fatores. Hillbrecht (1997), usando outra abordagem, encontrou evidências similares para o Brasil para o período anterior ao advento da Lei de Responsabilidade Fiscal (LRF).

Tabela 1 - Variações em Bem-estar e PIB das regiões selecionadas, Cenários 1 e 2

\begin{tabular}{|c|c|c|c|c|c|c|c|c|}
\hline \multirow{3}{*}{ 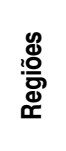 } & \multicolumn{4}{|c|}{ Cenário $1^{*}$} & \multicolumn{4}{|c|}{ Cenário $2^{\star *}$} \\
\hline & \multicolumn{2}{|c|}{ Bem-estar } & \multicolumn{2}{|c|}{ PIB } & \multicolumn{2}{|c|}{ Bem-estar } & \multicolumn{2}{|c|}{ PIB } \\
\hline & $\%$ & $\mathrm{R} \$$ milhões & $\%$ & $\mathrm{R} \$$ milhões & $\%$ & $\mathrm{R} \$$ milhões & $\%$ & R\$ milhões \\
\hline NOR & $-2,225$ & -2.726 & $-0,003$ & -6 & 2,225 & 2.726 & 0,003 & 6 \\
\hline NDE & $-2,207$ & -6.847 & $-0,001$ & -4 & 2,207 & 6.847 & 0,001 & 4 \\
\hline COE & $-2,219$ & -4.434 & $-0,002$ & -6 & 2,219 & 4.434 & 0,002 & 7 \\
\hline SDE & $-2,206$ & -25.424 & $-0,002$ & -33 & 2,206 & 25.424 & 0,002 & 33 \\
\hline SUL & $-2,193$ & -8.953 & 0,000 & -2 & 2,193 & 8.953 & 0,000 & 2 \\
\hline BRA & $-2,206$ & -48.384 & $-0,001$ & -51 & 2,206 & 48.384 & 0,001 & 52 \\
\hline
\end{tabular}

Fonte: Dados da pesquisa.

*Cenário 1: DF baixa, RO frouxa e MF intra-regional.

**Cenário 2: DF baixa, RO rígida e MF intra-regional.

No Cenário 2, com a imposição de restrição orçamentária rígida aos governos regionais, já se obtêm variações positivas no bem-estar e no PIB de todas as regiões e no agregado, muito embora para o PIB os ganhos ainda sejam marginais. A elevação no agregado foi de $2,21 \%$ e $0,001 \%$, respectivamente. O que se tem, portanto, é uma melhora na alocação de recursos da economia advindos do fato de se ter mais recursos à disposição das famílias vis-à-vis governos regionais com a redução do tamanho destes, gastando menos e, logo, arrecadando menos.

Isso é um primeiro elemento de prova da importância da austeridade fiscal subnacional, bastante negligenciada nos debates públicos no Brasil sobre reformas fiscais de longo prazo e na implantação de regras orçamentárias e institutos fiscais críveis e "enforceables". O recente caso no Brasil da aprovação de um teto de gastos somente para o Governo Federal e a ineficácia da LRF de conter o endividamento de vários estados deixam isso evidente. Corrobora também a literatura empírica de que maiores níveis de restrição orçamentária melhoram a eficiência da economia, ou inversamente, menores níveis pioram a economia (Rangel 2003). 
Na Tabela 2 são reportados os resultados para os cenários 3 e 4. Mantemse a mobilidade de fatores intra-regional com alteração de restrição orçamentária frouxa para rígida do cenário 3 para o 4 . A diferença é que se implementa descentralização fiscal denominada "alta", isto é, maior fatia da arrecadação tributária nas mãos dos governos regionais e menor dependência desses de transferências financeiras do governo central.

A consequência imediata dessa alteração é que a União reduz bastante sua capacidade de gasto, diminuindo despesas de consumo e transferências aos governos regionais (com o Sudeste e Nordeste com as maiores participações, sendo que para esta última região o impacto é ainda maior por causa do tamanho da sua economia) e às famílias (essas últimas possuem as maiores fatias do total de dispêndios da União). Em contrapartida, pelo lado das receitas, reduz-se também a necessidade de impostos federais e recebimento de transferências das famílias (com o Sudeste cedendo a maior parte nos dois casos).

Tabela 2 - Variações em Bem-estar e PIB das regiões selecionadas, Cenários 3 e 4

\begin{tabular}{|c|c|c|c|c|c|c|c|c|}
\hline \multirow{3}{*}{ 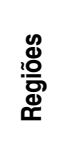 } & \multicolumn{4}{|c|}{ Cenário $3^{*}$} & \multicolumn{4}{|c|}{ Cenário $4^{* *}$} \\
\hline & \multicolumn{2}{|c|}{ Bem-estar } & \multicolumn{2}{|r|}{ PIB } & \multicolumn{2}{|c|}{ Bem-estar } & \multicolumn{2}{|r|}{ PIB } \\
\hline & $\%$ & $\mathbf{R} \$$ milhões & $\%$ & $\mathrm{R} \$$ milhões & $\%$ & R\$ milhões & $\%$ & R\$ milhões \\
\hline NOR & $-2,350$ & -2.878 & $-0,027$ & -56 & 2,100 & 2.574 & $-0,022$ & -45 \\
\hline NDE & $-1,929$ & -5.981 & $-0,021$ & -103 & 2,479 & 7.689 & $-0,021$ & -103 \\
\hline COE & $-1,667$ & -3.330 & $-0,003$ & -8 & 2,801 & 5.597 & 0,003 & 10 \\
\hline SDE & $-1,712$ & -19.731 & $-0,007$ & -131 & 2,712 & 31.251 & $-0,003$ & -65 \\
\hline SUL & $-0,778$ & -3.175 & 0,043 & 344 & 3,634 & 14.833 & 0,045 & 355 \\
\hline BRA & $-1,600$ & -35.095 & 0,001 & 46 & 2,824 & 61.944 & 0,004 & 151 \\
\hline
\end{tabular}

Fonte: Dados da pesquisa.

*Cenário 3: DF alta, RO frouxa e MF intra-regional.

**Cenário 4: DF alta, $\mathrm{RO}$ rígida e MF intra-regional.

Já os governos regionais aumentam a arrecadação tributária de base local (com as maiores participações do Centro-oeste, Sudeste e Sul em relação ao total) e perda de transferências recebidas do governo federal (com o Norte e Nordeste com maior dependência desses recursos). Eleva-se também o consumo em bens e serviços regionais e transferências às famílias (a maior fatia para o Sudeste). 
Assim sendo, começando pela comparação do cenário 3 com o cenário 1 , em que as condições de restrição orçamentária e mobilidade de fatores são as mesmas, o resultado a se destacar é de quedas menos pronunciadas em bem-estar em todas as regiões, exceto na região Norte, e no agregado, embora todas continuem negativas. Ou seja, mesmo num ambiente de déficits fiscais subnacionais e restrições na mobilidade, as famílias estarão em uma situação menos pior com governo descentralizado.

Quanto ao PIB, as quedas são mais pronunciadas no Norte, Nordeste, Centro-oeste e Sudeste com a descentralização e melhora na região Sul e no agregado para o Brasil (comparando-se o cenário 3 ao 1). Como os governos regionais gastam proporcionalmente mais em bens e serviços do que o governo federal, que usa a maior parte dos seus recursos para transferir para as famílias (dinheiro que agora está nas mãos das unidades subnacionais), a descentralização reforça o aumento da ineficiência produtiva ocorrido com os déficits fiscais do cenário 1 , mas agora indiretamente devido à redução dos recursos das famílias via diminuição das transferências do governo federal. No entanto, a região Sul é um verdadeiro outlier em termos de PIB, que é capaz inclusive de puxar o agregado do Brasil para cima.

Passando para o cenário 4 em comparação com o 3, com ativação da restrição orçamentária rígida há, novamente, reversão de perdas no bem-estar em todas as regiões e agregado. Contudo, dessa vez, conjugado com descentralização, o bem-estar agregado do Brasil atinge até o momento seu maior patamar, com variação positiva de $2,84 \%$ ou $R \$ 62$ bilhões. Logo, com ou sem restrição orçamentária rígida (num ambiente de mobilidade restrita de fatores), a descentralização fiscal melhora a posição das famílias.

Em relação ao PIB, há também melhoras na performance em todas as regiões com o agregado atingindo o seu maior patamar até então, 0,004\% ou $\mathrm{R} \$ 151$ milhões, ${ }^{32}$ sendo que a região Sul melhora a performance e a Centro-oeste passa a obter uma variação positiva.

Confrontando o cenário 4 com o 2 da Tabela 1, que possui RO rígida e migração de fatores apenas entre setores da mesma região, percebe-se

32 É válido mencionar que as diferenças de magnitudes nas variações de bem-estar e PIB aqui e nos demais resultados referem-se às diferenças conceituais e de construção da Matriz de Insumo Produto (MIP) e da Matriz de Contabilidade Social (MCS). Da primeira se extrai o valor do PIB e da segunda, que tem maior volume por considerar transferências de renda entre os agentes, o bem-estar. Esse fato também vai afetar as diferenças nas direções dos resultados em alguns cenários. 
também aumento generalizado no bem-estar com a descentralização fiscal, exceto para região Norte.

Mas quanto ao PIB, nessas mesmas condições, somente as regiões Centrooeste e Sul melhoram e o Sudeste tem uma pequena variação negativa. As maiores perdas são obtidas pelas regiões Norte e Nordeste. A explicação é que os governos regionais dessas regiões têm orçamentos que dependem em torno de $65 \%$ das transferências da União e que agora precisariam arcar com impostos os recursos perdidos com a descentralização numa proporção maior do que as demais, minando a competitividade do seus bens e serviços nas transações comerciais inter-regionais.

Essas são evidências de que descentralização é importante do ponto de vista das famílias e da eficiência econômica geral, mesmo com mobilidade de fatores restrita, como prevê a teoria (Oates 2005). Entretanto, corrobora as preocupações da literatura com os possíveis aumentos das disparidades regionais, especialmente em países como o Brasil (Cossio 1998).

Passa-se agora às análises dos resultados para os cenários 5 e 6 que constam da Tabela 3. Eles têm as seguintes características: retorna-se à descentralização fiscal baixa e com restrição orçamentária frouxa em um cenário e rígida no outro. A novidade é a inclusão da mobilidade de fatores inter-regional nos dois casos, elemento importante na geração de incentivos adequados para unidades subnacionais e, consequentemente, no estímulo positivo da economia nacional, muito enfatizado pela literatura do federalismo desde seu início.

No cenário 5, em comparação com o cenário 1 (os dois com descentralização fiscal baixa e restrição orçamentária frouxa), mantiveram-se as perdas do bem-estar no mesmo patamar para todas as regiões e agregado. O bem-estar geral diminuiu os mesmos 2,21\% ou R \$ 48 bilhões. 
Tabela 3 - Variações em Bem-estar e PIB das regiões selecionadas, Cenários 5 e 6

\begin{tabular}{|c|c|c|c|c|c|c|c|c|}
\hline \multirow{3}{*}{ 离 } & \multicolumn{4}{|c|}{ Cenário $5^{*}$} & \multicolumn{4}{|c|}{ Cenário $6^{* *}$} \\
\hline & \multicolumn{2}{|c|}{ Bem-estar } & \multicolumn{2}{|r|}{ PIB } & \multicolumn{2}{|c|}{ Bem-estar } & \multicolumn{2}{|c|}{ PIB } \\
\hline & $\%$ & R\$ milhões & $\%$ & R\$ milhões & $\%$ & R\$ milhões & $\%$ & RS milhões \\
\hline NOR & $-2,239$ & -2.742 & $-0,015$ & -32 & 2,239 & 2.742 & 0,015 & 31 \\
\hline NDE & $-2,209$ & -6.852 & $-0,003$ & -13 & 2,209 & 6.852 & 0,003 & 12 \\
\hline COE & $-2,234$ & -4.465 & $-0,015$ & -50 & 2,234 & 4.465 & 0,015 & 50 \\
\hline SDE & $-2,202$ & -25.375 & 0,002 & 41 & 2,202 & 25.375 & $-0,002$ & -42 \\
\hline SUL & $-2,192$ & -8.951 & 0,000 & 0 & 2,192 & 8.951 & 0,000 & -1 \\
\hline BRA & $-2,206$ & -48.384 & $-0,001$ & -53 & 2,206 & 48.384 & 0,001 & 51 \\
\hline
\end{tabular}

Fonte: Dados da pesquisa.

*Cenário 5: DF baixa, RO frouxa e MF inter-regional.

${ }^{* *}$ Cenário 6: DF baixa, RO rígida e MF inter-regional.

Em relação ao PIB, as regiões Norte, Nordeste e Centro-oeste pioram seus desempenhos (embora nos dois cenários essas variações sejam negativas). A região Sul e o agregado mantêm o mesmo desempenho e o Sudeste melhora ligeiramente a eficiência, inclusive passando para um patamar positivo.

O que ocorre é que num ambiente institucional fragilizado (descentralização fiscal baixa e restrição orçamentária frouxa) o Sudeste é a única região beneficiada com introdução de mobilidade de fatores entre as regiões, certamente porque ela recebe a maior parte das despesas em bens e serviços dos governos regionais maiores e das famílias beneficiadas com as transferências da União "centralizada", o que eleva os preços de capital e trabalho devido ao aumento da demanda, atraindo-os das outras regiões.

No Cenário 6, com imposição de restrição orçamentária rígida, o bem-estar de todas as regiões do Brasil e, consequentemente, no agregado, em relação ao 5, tornam-se positivos. Confrontando-se com o cenário 2 que possui mobilidade intra-regional, não há diferenças relevantes nas variações de bem-estar.

Assim, confirma-se definitivamente o postulado teórico óbvio de que exigir dos governos superávits melhora a situação das famílias em termos de renda disponível para consumir, dado que elas terão que pagar menos impostos. Este é o fator mais importante para explicar as variações em 
bem-estar. Novamente, reforça evidências encontradas anteriormente e provas empíricas da literatura da relevância de regras fiscais rígidas.

Quanto ao PIB, os resultados invertem de direção em relação ao cenário 5 em cada região. E em relação ao cenário 2 da Tabela 1, melhora o Norte, Nordeste e Sul com variações positivas $(0,015,0,003$ e 0,015 , respectivamente). Sudeste exibe variação negativa de $-0,002$, e Sul e PIB agregado mantêm o mesmo nível nos três casos (cenários 6, 5 e 2).

Ou seja, a permissão para mobilidade de fatores entre regiões aumenta ainda mais a eficiência alocativa obtida com a restrição orçamentária rígida nas regiões Norte, Nordeste e Centro-oeste e piora a do Sudeste, mantendo no mesmo patamar a do Sul e a do Brasil, num contexto de descentralização fiscal baixa.

Assim, nesse contexto, os fatores de produção são atraídos pelo aumento das remunerações advindo do aumento da demanda de bens e serviços das famílias nessas regiões possibilitado pelo repasse de recursos do governo federal. Por outro lado, as famílias do Sudeste, com o aumento da renda proveniente do governo regional menor, passam a transferir valores proporcionalmente mais altos vis-à-vis as demais para a União (que permanece grande sem descentralização), seguido pelo Sul. Daí os resultados mais modestos desses últimos.

Nesse ponto, vale destacar que alterações simétricas nos resultados do PIB e bem-estar advindos das mudanças na restrição orçamentária dos governos regionais dos cenários 1 para o 2 e do 5 para o 6 tem como fator comum a presença de descentralização fiscal baixa ou, dito de outra forma, a presença de centralização fiscal. Sendo assim, a evidência sugere que a relativa concentração de recursos no governo central e, por consequência, a rigidez na estrutura real de distribuição desses recursos entre regiões, ${ }^{33}$ materializada no modelo pela utilização de uma função Leontief para essa despesa, gera, por sua vez, rigidez nos resultados de indicadores econômicos comparados a uma estrutura fiscal mais descentralizada, em que há mais flexibilidade de distribuições de recursos regionalmente e de padrão de gastos.

33 Como exemplificado pelas regras constitucionais fixas de distribuição regional do FPE e FPM. 
Finalmente, a Tabela 4 mostra os resultados para os dois últimos cenários, sendo que o oitavo é o teste específico da hipótese do federalismo fiscal market-preserving. Nesses cenários, há descentralização fiscal alta com mobilidade de fatores inter-regional e restrição orçamentária frouxa no caso 7 e rígida no caso 8 .

Inicialmente, contrastando o cenário 7 com o cenário 5 (os dois cenários com restrição orçamentária frouxa e mobilidade inter-regional), a descentralização fiscal alta piorou o bem-estar das regiões Norte e Nordeste e reduziu as perdas do Centro-oeste, Sudeste, Sul e agregado para o Brasil, não obstante as variações tenham sido todas negativas (mas sabe-se que o fator determinante para as variações negativas nos dois cenários é a restrição orçamentária frouxa).

Relembrando que quando se tinha a mesma restrição orçamentária frouxa (então variações negativas no bem-estar em todas as regiões) mas num ambiente de mobilidade de fatores restrita, a descentralização fiscal alta melhorou o bem-estar para todos, exceto Norte, que se manteve praticamente no mesmo patamar. Isso sugere que a descentralização acompanhada de mobilidade inter-regional de fato aumenta a desigualdade.

Tabela 4 - Variações no Bem-estar e PIB das regiões, Cenários 7 e 8

\begin{tabular}{|c|c|c|c|c|c|c|c|c|}
\hline \multirow{3}{*}{ 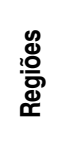 } & \multicolumn{4}{|c|}{ Cenário $7^{*}$} & \multicolumn{4}{|c|}{ Cenário $8^{\star *}$} \\
\hline & \multicolumn{2}{|c|}{ Bem-estar } & \multicolumn{2}{|r|}{ PIB } & \multicolumn{2}{|c|}{ Bem-estar } & \multicolumn{2}{|r|}{ PIB } \\
\hline & $\%$ & R\$ milhões & $\%$ & R\$ milhões & $\%$ & R\$ milhões & $\%$ & R\$ milhões \\
\hline NOR & $-3,027$ & -3.709 & $-0,599$ & -1.245 & 1,443 & 1.767 & $-0,577$ & -1.199 \\
\hline NDE & $-2,327$ & -7.217 & $-0,381$ & -1.832 & 2,060 & 6.391 & $-0,399$ & -1.917 \\
\hline COE & $-1,650$ & -3.297 & 0,006 & 20 & 2,873 & 5.740 & 0,059 & 191 \\
\hline SDE & $-1,714$ & -19.747 & $-0,018$ & -336 & 2,702 & 31.136 & $-0,022$ & -413 \\
\hline SUL & $-0,247$ & -1.009 & 0,469 & 3.739 & 4,172 & 17.033 & 0,477 & 3.800 \\
\hline BRA & $-1,595$ & -34.978 & 0,009 & 347 & 2,830 & 62.066 & 0,012 & 463 \\
\hline
\end{tabular}

Fonte: Dados da pesquisa.

*Cenário 7: DF alta, RO frouxa e MF inter-regional.

**Cenário 8: DF alta, RO rígida e MF inter-regional. 
Quanto ao PIB, novamente Norte e Nordeste obtiveram variações negativas maiores que no cenário 5. Quedas expressivas de -0,599 e -0,381, respectivamente. O Centro-oeste passou de um resultado negativo de 0,015 para um positivo de 0,006 , enquanto o Sudeste fez o caminho inverso, alta de 0,002 para queda de $-0,018$. O Sul foi a região que mais se beneficiou com um aumento substancial 0,469 ou $\mathrm{R} \$ 3,7$ bilhões, sendo que o desempenho do PIB agregado líquido foi de 0,009 positivo (contra -0,001 em 5). Essas últimas evidências parecem indicar um movimento dos fatores de produção do Sudeste para o Sul atraídos pelo bom desempenho do seu setor produtivo e da menor participação relativa em pagamento de impostos e transferências das famílias dessa região para o governo federal .

Quanto ao cenário 8, que impõe restrição orçamentária rígida com descentralização fiscal alta e mobilidade de fatores inter-regional, os resultados basicamente confirmam o que foi exposto até aqui e, em nível nacional, respalda a formulação teórica do FMP.

A performance do bem-estar e do PIB agregados alcançam a mais alta variação de aumento de todos os cenários $(2,83 \%$ e $0,012 \%$, respectivamente). Regionalmente, ganhos de bem-estar em todas as regiões e variações negativas no PIB do Norte $(-0,577)$, Nordeste $(-0,399)$ e Sudeste $(-0,022)$, e positivas para Centro-oeste $(0,059)$ e $\mathrm{Sul}(0,477)$. As perdas maiores do Norte e Nordeste são esperadas em função da alta dependência dos seus governos regionais de transferências da União, que reduz de tamanho com a descentralização.

Como antes, isso ocorre porque a concessão de maior autonomia financeira para estados e municípios diminui a carga tributária de impostos federais dos setores das regiões Centro-oeste, Sudeste e Sul tornando-os mais competitivos, conjuntamente com a redução de repasses federais de recursos às famílias e governos regionais do Norte e Nordeste, já que o orçamento da União sofre redução, afetando a demanda de produtos locais. Consequentemente, isso tende a elevar o produto das três maiores regiões, que, por sua vez, puxa o PIB agregado para cima.

Trabalhos como de Guedes e Gasparini (2007) e Gadelha (2012) encontraram resultados semelhantes para o Brasil de efeitos benéficos da descentralização na economia nacional, usando modelos econométricos. E quanto à restrição orçamentária, os trabalhos de Nakaguma e Bender (2006) e Giuberti (2005) reforçam as evidências positivas para o Brasil ao 
demonstrar que normas nos moldes da Lei de Responsabilidade Fiscal, que procuram impor Restrição Orçamentária Rígida, são eficazes em reduzir déficits subnacionais e melhorar a eficiência econômica. Muito embora o caráter, para usar o termo da literatura do FMP, self-enforcing desse perfil de lei ou o tipo de regra fiscal, seja mais importante a longo prazo do que os efeitos de curto e médio prazo (Pires e Bugarin 2003).

Sendo assim, destacam-se algumas análises finais: pode-se afirmar, por exemplo, que dentro de uma estrutura de equilíbrio geral, os resultados apontaram para direção de que o encadeamento do gasto privado gera mais eficiência do que do gasto público. Inclusive, a performance diferenciada da região Sul corrobora esse fato porque, na base de dados, suas famílias detêm um orçamento disponível para consumo relativamente maior do que as demais.

As evidências parecem sugerir que a descentralização fiscal, especialmente num ambiente de maior mobilidade de fatores, retroalimenta os efeitos positivos das políticas de austeridade, redirecionando a maior parte dos recursos do país para o setor produtivo ou real e encurtando a distância entre o recurso gerado e o dispêndio nesse mesmo setor, por meio da redução do volume de transferências financeiras entre os agentes da economia.

E ainda, o nível de descentralização fiscal e da mobilidade de fatores pode ser decisivo para determinar quais regiões serão ganhadoras e perdedoras que, no final das contas, resumem-se a dois grupos que se movimentam em direções contrárias: Norte e Nordeste por um lado e Centro-oeste, Sudeste e Sul, por outro. Isso atesta as recorrentes ressalvas da literatura quanto aos possíveis efeitos prejudiciais desse tipo de regime fiscal para regiões pouco desenvolvidas em países com grande heterogeneidade econômica. ${ }^{34}$

Rodden e Rose-Ackerman (1997), por exemplo, preveem a possibilidade de resultado desigual entre regióes ao afirmar que o FMP tende a exagerar as disparidades regionais. Nessa linha, Cossio (1998) mostrou indícios de que as diferenças socioeconômicas inter-regionais no Brasil podem ser um sério impedimento para a superação de crises fiscais no federalismo brasileiro. Simonassi e Cândido Junior (2008) acharam resultados indi-

${ }^{34}$ Embora o Sudeste tenha tido leva queda do PIB nos dois últimos cenários, em simulações adicionais com implementação de descentralização fiscal mais aguda (União com $20 \%$ e governos regionais com $80 \%$ dos impostos e redução de 66 pontos percentuais das transferências daquele para estes) ele retoma as variações positivas. Ademais, Norte e Nordeste acentuam as perdas e Centro-oeste e Sul aumentam os ganhos. Isso confirma que esta é a tendência dos resultados e respalda o que foi dito. 
cando que o desempenho fiscal dos estados no Brasil é substancialmente influenciado pelas altas discrepâncias sociais, políticas e econômicas entre regiões brasileiras.

Por outro lado, a expectativa, por parte do FMP (Weingast 2014, Weingast 2009), é que, com o passar do tempo, os governos que perdem trabalho e capital atuem no sentido de reverter esse quadro, buscando criar um ambiente favorável à atividade econômica.

Acontece que no Brasil o uso excessivo e prolongado dos mecanismos de transferência para equalização de renda regional neutraliza tal reação, porque as perdas de base tributária são continuamente compensadas e, de certa forma, recompensadas. Callado (2005) não encontrou indicativos de que essas políticas atinjam os objetivos redistributivos alardeados. Por outro lado, trabalhos como o de Guedes e Gasparini (2007) mostram como a alta participação das transferências nos orçamentos de estados e municípios pode reverter efeitos positivos da descentralização fiscal.

A Figura 1 resume as descobertas para o PIB agregado brasileiro. Destacam-se três observações: $(i)$ a mais importante é a de que o FMP (cenário 8 - mais alto grau) gera um desempenho econômico melhor do que em todos os outros experimentos, e a sua exata contraparte - cenário 1, o pior resultado (assim como o cenário 5); (ii) restrição orçamentária rígida sempre melhora a eficiência econômica (cenários 1 para o 2; 3 para o 4; 5 para o 6; e 7 para o 8); e (iii) duas condições do FMP implementadas juntas são sempre melhor que somente uma, sendo que descentralização fiscal em combinação com qualquer outra é mais relevante do que a combinação das duas outras e a mobilidade de fatores inter-regional é mais importante do que a restrição orçamentária rígida para se aumentar a performance do PIB.

Já a Figura 2 condensa os achados para o bem-estar geral das famílias. Os principais resultados são: (i) novamente confirmação da hipótese do FMP devido à maior variação positiva para o cenário 8 e menor para o cenário 1 ; (ii) a restrição orçamentária rígida é, destacadamente, em termos de bem-estar, a condição mais crucial para melhorar a performance. Na verdade, é ela quem torna as variações positivas possíveis; (iii) a descentralização fiscal alta sempre melhora os resultados e o tipo de migração de fatores não altera o bem-estar agregado. 


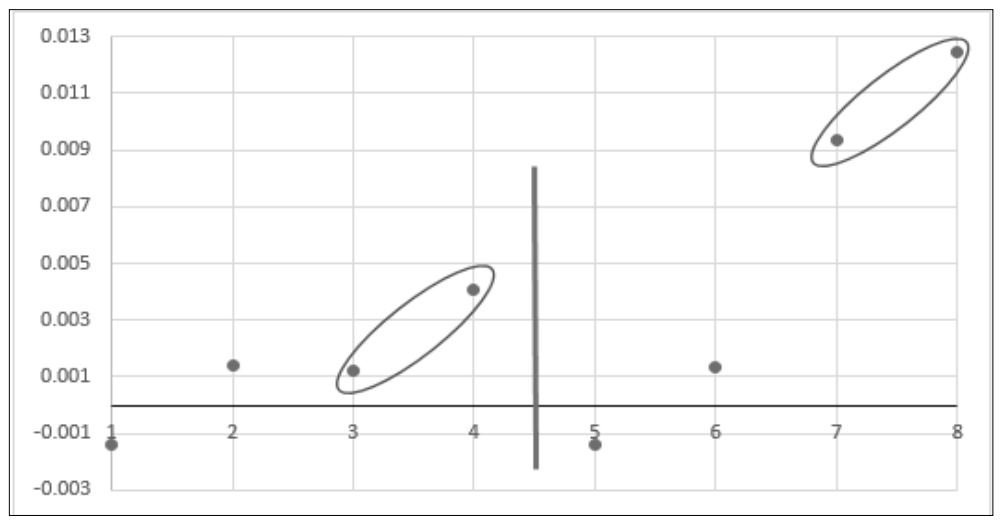

Figura 1 - Variação percentual do PIB brasileiro (eixo vertical) para cada cenário (eixo horizontal)

Fonte: Dados da pesquisa.

Nota: Os cenários pares possuem restrição orçamentária rígida; nos quatros pontos circulados implementa-se descentralização fiscal alta nos cenários correspondentes; e os quatros primeiros cenários à esquerda da linha vertical verde contam com mobilidade intra-regional e os quatro a direita com mobilidade inter-regional.

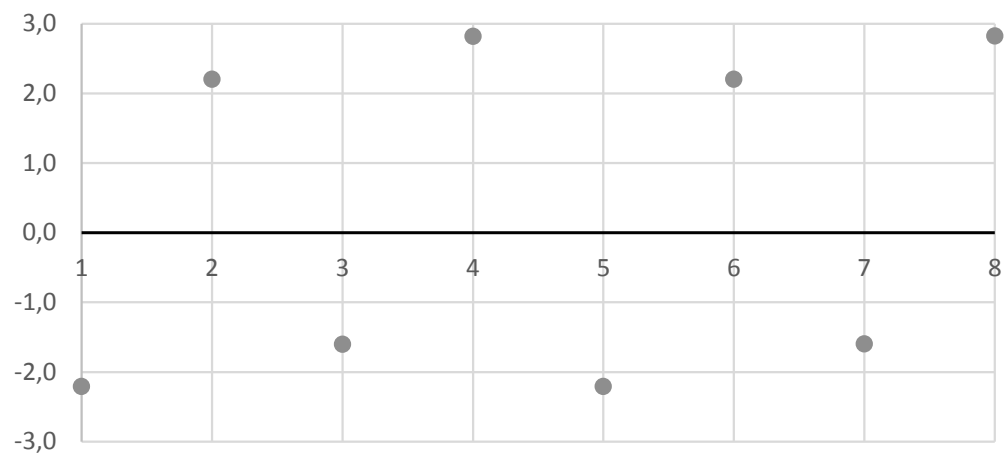

Figura 2 - Variação percentual em Bem-estar agregado brasileiro (eixo vertical) para cada cenário (eixo horizontal)

Fonte: Dados da pesquisa.

Em seguida, apresenta-se a Figura 3 com os resultados do PIB para cada cenário em nível regional. De maneira geral, fica evidente que o elemento decisivo para o distanciamento de desempenho das regiões é a combinação de descentralização fiscal com mobilidade de fatores inter-regional presentes nos dois últimos cenários: (i) região Sul e Centro-oeste com 
desempenho positivo; (ii) Sudeste com leve variação negativa embora com viés de alta; ${ }^{35}$ e (iii) regiões Norte e Nordeste com bem-estar negativos.

Por fim, na Figura 4 são exibidas as variações percentuais do bem-estar das famílias regionalmente. O que se percebe é que as regióes possuem o mesmo padrão de variação do bem-estar agregado destacado acima, sendo que os melhores resultados em ordem crescente são: Norte, Nordeste, Sudeste, Centro-Oeste e Sul.

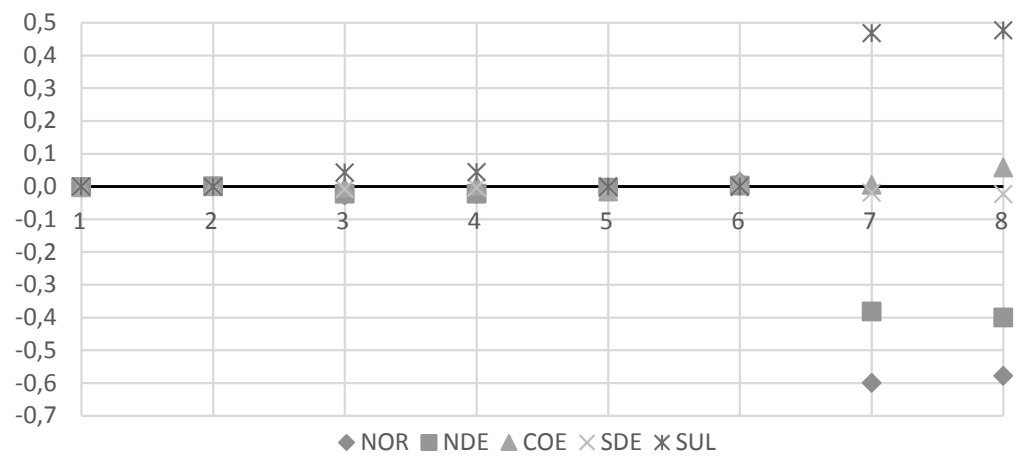

Figura 3 - Variação percentual no PIB por grande região (eixo vertical) para cada cenário (eixo horizontal)

Fonte: Dados da pesquisa.

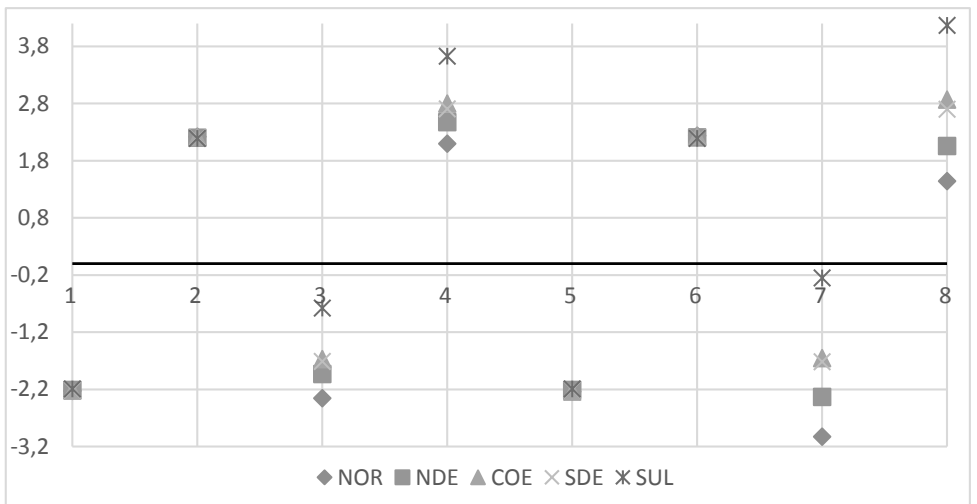

Figura 4 - Variação percentual em Bem-estar por grande região (eixo vertical) para cada cenário (eixo horizontal)

Fonte: Dados da pesquisa.

35 Conforme próxima faixa de descentralização fiscal acentuada sugere, de acordo com nota anterior. 


\section{Conclusões}

O objetivo central deste artigo foi testar empiricamente para o Brasil a validade da principal proposição do federalismo market-preserving, qual seja: atendidas determinadas condições no sistema federativo haverá ganhos econômicos para a nação. Para tal, foram conduzidos diversos experimentos em um modelo de equilíbrio geral computável, que buscaram captar as principais características desse tipo de federalismo. No caso brasileiro, significa implementar maior descentralização fiscal ancoradas pela imposição de restrição orçamentária rígida e maior mobilidade de fatores de produção.

De maneira geral, os resultados confirmaram a hipótese do FMP: a concessão de maior autonomia tributária aos governos regionais, acompanhada ou disciplinada por imposição de restrição orçamentária rígida e mobilidade de fatores inter-regional, aumenta o PIB e o bem-estar, embora em nível regional os resultados tenham sido desiguais e em direções diferentes. As regiões Norte e Nordeste obtiveram perdas maiores no PIB em função da migração de fatores e descentralização fiscal, ainda que, em termos de bem-estar, a restrição orçamentária rígida garanta bom desempenho para todas as regiões indistintamente.

Logo, as recomendações de política seriam no sentido de procurar estabelecer para governos regionais base tributária própria equivalente à receita disponível, isto é, minimizar a participação das transferências, e elevada restrição de endividamento para financiar gastos. Na verdade, déficits poderiam ser limitados constitucionalmente sem nenhuma perspectiva de resgates financeiros da União. Como os incentivos políticos quase sempre induzem ao comportamento contrário, sugere-se propor uma lei no congresso proibindo terminantemente a União de resgatar financeiramente qualquer governo.

Adotar também medidas que minimizem restrições à livre movimentação de capital e trabalho favorecendo uma determinação competitiva da escolha ótima de carga tributária e gasto público (inclusive da composição: despesas de capital vis-à-vis despesas correntes) com vistas a fomentar a atividade econômica local. Isso poderia ser feito melhorando a segurança jurídica de modo geral (aumentando a probabilidade de fechamento de bons contratos de trabalho e investimento) e despesas em infraestrutura de transporte e telecomunicações. 
Sugere-se investigar com mais detalhes os impactos da implementação do Federalismo Market-preserving nas desigualdades regionais. Essa é uma questão de extrema relevância por seu caráter histórico, conflitivo e com potencial para alterar os rumos de reformas econômicas vitais para o Brasil. Inclusive propõe-se o uso de modelos dinâmicos de EGC a fim de se checar se os governos de fato respondem no tempo aos incentivos impostos pelo FMP.

Por último, algumas das limitações deste artigo a serem enfrentadas no futuro são: a mensuração mais precisa dos parâmetros de mobilidade do capital e trabalho entre regiões; a implementação de resultados fiscais mais realistas em termos de balanço orçamentário dos governos; e o uso de formas funcionais mais flexíveis para os gastos públicos.

\section{Referências}

Abreu, Marcelo P. 1990. “A ordem do progresso". Rio de Janeiro: Campus.

Aguiar, Angel, Badri Narayanan, and Robert McDougall. 2016. “An Overview of the GTAP 9 Data Base.” Journal of Global Economic Analysis 1(1): 181-208.

Callado, Marcelo C. 2005. "Sobre a História e estrutura atual do Federalismo Fiscal no Brasil." Tese de Doutorado, Universidade de Colônia.

Cossio, Fernando, A. B. 2002. "Ensaios sobre federalismo fiscal no Brasil.” Tese de Doutorado, Pontifícia Universidade Católica do Rio de Janeiro.

Cossio, Fernando, A. B. 1998. "Disparidades econômicas inter-regionais, capacidade de obtenção de recursos tributários, esforço fiscal e gasto público no federalismo brasileiro.” Rio de Janeiro: Banco Nacional de Desenvolvimento Econômico e Social.

de Figueiredo Jr, Rui J. P., and Barry R. Weingast. 2005. "Self-enforcing federalism.” The Journal of Law, Economics and Organization 21(1): 103-135.

Dixon, Peter B., M. Picton, and Maureen T. Rimmer. 2002. “Australian Federalism: a CGE analysis of intergovernment transfers.” The $5^{\text {th }}$ Conference on Global Economic Analysis, Conference Papers.

Feijó, Carmem A., and Roberto L. O. Ramos. 2013. "Contabilidade social: a nova referência das contas nacionais do Brasil". Rio de Janeiro: Campus.

Fochezatto, Adelar. 2003. "Construção de um modelo de equilíbrio geral computável regional: aplicação ao Rio Grande do Sul.” Texto para Discussão n. 944, IPEA.

Gadelha, Sérgio R. B. 2012. “Analisando o Impacto da Descentralização Fiscal na Saúde Pública: Evidência Empírica para os Municípios Brasileiros (2000-2009).” Texto para Discussão n. 12, Tesouro Nacional.

Giuberti, Ana Carolina. 2005. "Efeito da lei de responsabilidade fiscal sobre os gastos dos municípios brasileiros." Dissertação de Mestrado, Universidade de São Paulo. 
Guedes, Kelly P., and Carlos E. Gasparini. 2007. “Descentralização fiscal e tamanho do governo no Brasil.” Economia Aplicada 11(2): 303-323.

Gurgel, Angelo C. 2002. "Impactos econômicos e distributivos de mudanças nas relações comerciais da economia brasileira na presença de economias de escala.” Tese de Doutorado, Universidade Federal de Viçosa.

Hertel, Thomas W. 1997. "Global trade analysis: modeling and Applications”. New York: Cambridge University Press.

Hillbrecht, Ronald O. 1997. "Federalismo e a união monetária brasileira.” Estudos Econômicos 27(1): 53-67.

Nechyba, Thomas. 1996. “A computable general equilibrium model of intergovernmental aid.” Journal of Public Economics 62(3): 363-397.

Martell, Christine R. 2008. "Fiscal institutions of Brazilian municipal borrowing." Public Administration and Development 28(1): 30-41.

Musgrave, Richard A. 1959. "The theory of public finance". New York: McGraw-Hill.

Nakaguma, Marcos Y., Siegfried Bender. 2006. "A emenda da reeleição e a Lei da Responsabilidade Fiscal: impactos sobre ciclos políticos e performance fiscal dos Estados." Economia Aplicada 10(3): 377-397.

Oates, Wallace E. 1972. "Fiscal federalismo". New York: Harcourut Brace Jovanovich.

Palermo, Patrícia U., Alexandre A. Porsse, and Marcelo S. Portugal. 2013. "Impactos regionais da reforma tributária: lições de uma análise EGC para o Rio Grande do Sul.” Pesquisa e Planejamento Econômico 43(3): 585-624.

Pereira, Matheus W. G. 2011. "Efeitos de políticas tributárias e de liberalização comercial sobre a competitividade setorial das macrorregiões brasileiras.” Tese de Doutorado, Universidade Federal de Viçosa.

Pires, Henrique A. A., and Maurício S. Bugarin. 2003. "Metas de déficit: Transferências intergovernamentais e o controle do endividamento dos Estados." Revista Brasileira de Economia 57(4): 775-794.

Porsse, Alexandre. A. 2005. "Competição tributária regional, externalidades fiscais e federalismo no Brasil: uma abordagem de equilíbrio geral computável.” Tese de Doutorado, Universidade Federal do Rio Grande do Sul.

Rangel, Marcos A. 2003. "Resgates financeiros, restrição orçamentária fraca e postura fiscal nos estados brasileiros.” Dissertação de Mestrado, Pontifícia Universidade Católica do Rio de Janeiro.

Rezende, Fernando, and José R. Afonso. 2004. “A federação brasileira: fatos, desafios e perspectivas." Federalismo e integração econômica regional - desafios para o Mercosul. Rio de Janeiro: Konrad Adenauer.

Rutherford, Thomas F. 1999. "Applied general equilibrium modeling with MPSGE as a GAMS subsystem: an overview of the modeling framework and syntax." Computational Economics 14(1): 1-46.

Rodden, Jonathan, and Suan Rose-Ackerman. 1997. “Does Federalism Preserve Markets?” Virginia Law Review 83(7): 1521-72.

Salami, Carlos R., and Adelar Fochezatto. 2009. "Avaliando os Impactos de Políticas Tributárias Sobre a Economia Brasileira com Base em um Modelo de Equilíbrio Geral de Gerações Sobrepostas." Revista Brasileira de Economia 63(3): 299-314.

Serra, Jose, and Jose R. Afonso. 1999. "Federalismo fiscal à brasileira: algumas reflexões." Revista do BNDES 6(12): 3-30.

Simonassi, Andrei G., and José O. Cândido Júnior. 2008. "Desempenho Fiscal e os impactos sobre as responsabilidades fiscal e social nos Estados e Regiões brasileiras.” Texto para Discussão, n. 1323, IPEA.

Teixeira, Erly C., Matheus W. G. Pereira, and Angelo C. Gurgel. 2013. "A Estrutura do PAEG”. Campo Grande: Life Editora.

Tiebout, Charles M. 1956. “A pure theory of local expenditures.” Journal of Political Economy 64(5): 416-424.

Varsano, Ricardo. 1996. "A evolução do sistema tributário brasileiro ao longo do século: anotações e reflexões para futuras reformas.” Texto para Discussão n. 405, IPEA.

Weingast, Barry R. 2014. "Second generation fiscal federalism: political aspects of decentralization and economic development." World Development 53: 14-25. 
Weingast Barry R. 2009 "Second generation fiscal federalism: The implications of fiscal incentives.” Journal of Urban Economics 65(3): 279-293.

Weingast, Barry R. 2005. “The performance and stability of federalism: an institutional perspective.” Handbook of New Institutional Economics, 149-172.

Weingast, Barry R. 1995. "The economic role of political institutions: market-preserving federalism and economic development." Journal of Law, Economics and Organization 11(1): 1-31. 